\title{
Principais Desafios para a Inclusão dos Docentes da Rede Pública no Contexto das Tecnologias da Informação e Comunicação
}

\author{
Rosane Rodrigues Feitosa ${ }^{1}$, Keylla Maria de Sá Urtiga Aita ${ }^{2}$, Aline Montenegro \\ Leal Silva ${ }^{2}$ \\ ${ }^{1}$ Curso de Licenciatura em Computação - Universidade Federal do Piauí (UFPI) - \\ Universidade Aberta do Brasil (UAB) - Polo de Inhuma \\ 64049-550 - Teresina - PI- Brasil \\ ${ }^{2}$ Centro de Educação Aberta e à Distância - Universidade Federal do Piauí (UFPI) - \\ Rua Olavo Bilac, 1148, 64001-280, Teresina - PI- Brasil \\ rodriguesfeitosarosane@gmail.com, keyllaurtiga@ufpi.edu.br, alineleal5@yahoo.com.br
}

\begin{abstract}
Nowadays, the increasing technological advance has demanded a new reality of knowledge and information. However, following such changes has been a very arduous task for most people, especially for public school teachers with many years of training. This study presents a research with a group of elementary school teachers from the Luis Pedro de Carvalho Municipal School, in the municipality of Inhuma - PI. The results demonstrate the difficulties faced regarding the use of technological resources in the room, becoming a challenge to the use of these resources in the pedagogical practices of teachers.
\end{abstract}

Resumo. Atualmente, o crescente avanço tecnológico tem exigido uma nova realidade de conhecimento e informação. Porém, seguir tais mudanças tem sido uma tarefa muito árdua para a maioria das pessoas, sobretudo, para os docentes da rede pública com muitos anos de formação. Este estudo apresenta uma pesquisa com um grupo de professores do Ensino Fundamental da rede pública da Escola Municipal Luís Pedro de Carvalho, no município de Inhuma - PI. Os resultados demonstram as dificuldades enfrentadas quanto ao uso dos recursos tecnológicos em sala de sala, tornando-se um desafio a utilização desses recursos nas práticas pedagógicas dos docentes.

\section{Introdução}

As tecnologias evoluem de forma rápida e ocupam um papel de destaque, exigindo das instituições de ensino e dos educadores urgência em se adequar ao uso de recursos tecnológicos nas práticas educativas. Para que isso aconteça, é preciso apresentar novas formas de adquirir conhecimentos e as instituições formadoras de docentes precisam agregar aos seus conteúdos curriculares as tecnologias no processo de ensino e aprendizagem. [Santos et al. 2017]

No universo escolar dos dias atuais, é indiscutível a importância da tecnologia juntamente com seus recursos multimídias dentro da escola, mas sabemos que inserir tais ferramentas tecnológicas não é um processo simples e nem tão pouco surtirá efeitos benéficos de forma automática. Antes da inserção das Tecnologias de Informação e Comunicação (TICs) na escola, é preciso formação adequada dos seus profissionais para 
VIII Congresso Brasileiro de Informática na Educação (CBIE 2019)

Anais do XXV Workshop de Informática na Escola (WIE 2019)

que, por meio deles, a escola torne-se um espaço de aprendizagem prazeroso, dinâmico e muito mais inovador. Atualmente um dos grandes desafios sofridos pela educação, na maior parte das escolas do nosso município, é causado, inclusive, pela pouca ou quase nenhuma utilização dessas tecnologias pelos professores em suas práticas pedagógicas, a despeito do que essas práticas poderiam potencializar o processo de ensino e aprendizagem. Dentre os fatores preponderantes que contribuem para o pouco uso das TICs nas escolas, tem-se: a falta de incentivo na formação continuada dos docentes e a tecnofobia sofrida por alguns professores frente às TICs, o que dificulta tanto a utilização como a aprendizagem dos próprios docentes quanto ao domínio destes recursos tecnológicos.

Nesse artigo apresentam-se os resultados de uma pesquisa de campo realizada na Escola Luís Pedro de Carvalho, da rede pública de ensino do município de Inhuma- PI. O estudo foi realizado com 8 (oito) professores das séries de $6^{\circ}$ ao $9^{\circ}$ do ensino fundamental e com o grupo gestor da escola, através de um questionário de 10 questões mistas (objetivas e subjetivas) para averiguar quais as principais dificuldades enfrentadas pelos docentes ao usarem recursos tecnológicos em sala de aula e se a subutilização desses recursos no processo educativo é devido à falta de formação ou por medo de não saberem utilizar tais ferramentas.

A pesquisa objetivou averiguar se os principais desafios enfrentados pelos professores quanto ao uso das TICs relatados na literatura configuram também a realidade presente no âmbito das escolas públicas do município de Inhuma. Tais desafios são: falta de formação continuada, falta de domínio das ferramentas tecnológicas e a tecnofobia, ou seja, medo de que os alunos saibam utilizar as TICs mais do que os próprios professores. Os resultados revelaram a importância da formação continuada para os docentes com a inclusão e utilização dos recursos tecnológicos nas práticas pedagógicas. A partir dos resultados, elencaram-se as formas de quebrar as barreiras da tecnofobia sofrida pelos docentes, quanto ao uso dos novos recursos midiáticos em sala de aula, bem como apontou alternativas que possam solucioná-la ou pelo menos amenizar estes empasses sofridos pelos professores em suas práticas cotidianas.

As próximas seções desse trabalho encontram-se estruturadas da seguinte forma: a seção 2 aborda a fundamentação teórica referente à utilização das TICs na escola e sua importância para os dias contemporâneos; a seção 3 exibe o método de pesquisa aplicado para coleta de dados; a seção 4 apresenta os resultados dessa pesquisa por meio de gráficos, seguidos das discursões e por último, a seção 5 se destina à conclusão obtida nesse trabalho, bem como as perspectivas para trabalhos futuros.

\section{O uso das TICs na Escola}

Vive-se em um mundo cada vez mais tecnológico, com grande velocidade no compartilhamento de informações e otimização de tarefas que antes eram dissociadas das Tecnologias Digitais da Informação e Comunicação (TDIC). Esta realidade é fortemente vista no campo da Educação, no qual os recursos computacionais fazem-se, dia a dia, mais presentes no ambiente escolar, fato esse que vem modificando e incrementando o processo de ensino e aprendizagem. [Silva et al. 2018]

Hoje em dia tem-se presenciado com grande frequência os gestores escolares bancarem as escolas com altos e sofisticados investimentos para instalações dos recursos materiais, espaços físicos de laboratórios de informática, TVs, vídeos, DVDs, 
VIII Congresso Brasileiro de Informática na Educação (CBIE 2019)

Anais do XXV Workshop de Informática na Escola (WIE 2019)

material de videoconferência, entre outros, e não investirem na formação continuada dos professores. Receoso de estar perdendo espaço para as máquinas, o professor acaba se estagnando e não se modernizando, o que torna todo o gasto com a infraestrutura tecnológica um desperdício, pois será aplicada de maneira superficial e sem proveito significativo. Segundo Peña (2004):

\begin{abstract}
"Para que o professor passe de um ensino convencional a um ensino apoiado nas novas tecnologias, bem como desenvolvido em ambientes virtuais, exige que a instituição estabeleça o desenvolvimento de um projeto de formação de professores que priorize a inserção das TICs numa perspectiva construtiva e reflexiva da ação docente."
\end{abstract}

Todavia, é possível que esta seja uma maneira de acrescentar a motivação nos educadores para buscarem sua formação frente às novas tecnologias que a sociedade lhe oferece, adequando assim, melhorias no processo de ensino e aprendizagem, atraindo, cada vez mais o interesse em achar novas formas de pesquisa e conhecimento.

Como já se havia dito anteriormente, é percebível a necessidade de equipar as escolas com os mais diversos aparatos tecnológicos, entretanto, as tecnologias sozinhas não mudam a escola, mas trazem mil possibilidades de apoio ao professor e de interação com e entre os alunos, assim nos informa Moran (2004). Nutridos de pensamentos como estes, os docentes devem sempre buscar meios para que possam aprender e incorporar estas ferramentas nas suas práticas pedagógicas para que, de tal modo, possam utilizálas como uma ferramenta de apoio para o conhecimento de ambos.

Os pensamentos de Moran (2004) e Peña (2004) mostram-se alinhados no que se referem aos desafios enfrentados pelos professores na utilização das TICs no processo de ensino e aprendizagem. Moran (2004) defende a ideia de que o novo professor tem que aprender a gerenciar e integrá-las ao seu ensino e Peña (2004) afirma que o desafio que se impõe hoje aos professores é reconhecer que os novos meios de comunicação e linguagens presentes na sociedade devem fazer parte da sala de aula, não como dispositivos tecnológicos que imprimem certa modernização ao ensino, mas sim conhecer a potencialidade e a contribuição que as TICs podem trazer ao ensino como recurso e apoio pedagógico às aulas presenciais e ambientes de aprendizagem no ensino a distância.

Ainda a respeito da importância da capacitação dos professores para trabalhar com as novas tecnologias e as possibilidades de um repensar de suas práticas pedagógicas fortalecendo a ação didático-pedagógica, Almeida (2000) pontua que:

\begin{abstract}
"O professor com uma atitude crítico-reflexiva diante de sua prática trabalha em parceria com os alunos na construção cooperativa do conhecimento, promove-lhes a fala e o questionamento e considera o conhecimento sobre a realidade que o aluno traz para construir um saber cientifico que continue a ter significado. Para tanto, é preciso desafiar os alunos em um nível de pensamento superior ao trabalho no treinamento de habilidades e incitá-los a aprender."
\end{abstract}

Sabemos que a educação é um processo contínuo e de longo prazo, sendo formada da junção de um conjunto de fatores que se agregam para obter um bom resultado. Vivemos hoje em uma sociedade dinâmica, de múltiplas oportunidades de aprendizagem, chamada também por muitos de sociedade da informação, uma sociedade de aprendizagem global, na qual as consequências para a escola, para o docente e para a educação em geral, são enormes. Conforme Oliveira (2007):

"A participação da escola nesse novo cenário é fundamental para o êxito na formação de alunos capazes de atuar de forma crítica e autônoma na sociedade. $O$ 
VIII Congresso Brasileiro de Informática na Educação (CBIE 2019)

Anais do XXV Workshop de Informática na Escola (WIE 2019)

professor deve interagir com os alunos, saber utilizar as TICs e delas tirar vantagens, principalmente para assegurar a seus alunos o conhecimento que os levará a serem cidadãos com competências e habilidades para participarem dos processos da sociedade digital."

Em decorrência das atuais transformações sofridas pelas inovações tecnológicas, faz-se necessário ao ser humano aprender a pensar autonomamente, saber comunicar-se, saber pesquisar, saber fazer, ter raciocínio lógico, aprender a trabalhar em equipe, saber organizar o próprio trabalho, ser disciplinado, ser sujeito da construção do conhecimento, estar aberto a novas aprendizagens, conhecer as fontes de informação, saber articular o conhecimento com a prática e com outros saberes integrando ensino e vida, conhecimento e ética, reflexão e ação, tendo uma visão total do mundo.

Ao mesmo tempo, é importante ressaltar que não basta apenas ter acesso aos novos utensílios tecnológicos, mas é preciso ter a consciência de que uma aula lecionada utilizando estas novas tecnologias na sua prática metodológica exige outro desafio a ser enfrentado pelo professor, que é preparar esse ambiente e ter condições de lidar com as ferramentas que se irá utilizar e buscar identificar a intimidade que o aluno tem com determinada ferramenta. Segundo Faria (2004):

\begin{abstract}
"Planejar uma aula com recursos de multimeios exige preparo do ambiente tecnológico, dos materiais que serão utilizados, dos conhecimentos prévios dos alunos para manusear estes recursos, do domínio da tecnologia por parte do professor, além de seleção e adequação dos recursos à clientela e aos objetivos propostos pela disciplina."
\end{abstract}

Valente (2005), em outra vertente, também nos alerta para o risco da inclusão tecnológica em sala de aula. Ele afirma que é de grande relevância entender que cada tecnologia tem características próprias, vantagens e desvantagens, as quais têm de ser mencionadas e discutidas para que possam ser usadas no trabalho docente. Portanto, cabe aos docentes buscar novas metodologias para ensinar e se apropriar destes recursos tecnológicos, porque senão, mesmo com a utilização de ferramentas tecnológicas, a aula pode se tornar a velha aula tradicional.

Com base nas ideias desses importantes autores, é possível observar que eles reconhecem as necessidades e desafios enfrentados pelos professores em incorporar tais recursos como ferramentas midiáticas nas suas práticas, ao tempo em que destaca que é necessário aos docentes estarem atentos e aptos aos novos meios de comunicação e linguagens que a sociedade vem lhes impondo como meio de novos saberes, pois a utilização desses recursos tecnológicos pode proporcionar aos seus alunos novos horizontes e alargar seus conhecimentos através de métodos muito mais inovadores, desde que, como destaca Valente (2005), os docentes saibam como bem introduzir tais recursos em suas práticas.

Além da parcela de auto aprimoramento atribuída aos profissionais, é também dever das próprias instituições educacionais equipar e dar os subsídios necessários aos seus funcionários, principalmente aos docentes, para acompanhar tais evoluções tecnológicas. Um meio de tornar apto esses novos recursos seria através de políticas públicas, das quais poderiam adquirir formações adequadas para a utilização das TICs no processo de ensino e aprendizagem. Para Ferreira (2014), essas novas tecnologias trouxeram grande impacto para a educação, criando novas formas de aprendizado, disseminação do conhecimento e especialmente, novas relações entre professor e aluno. Existe hoje grande preocupação com a melhoria da escola, expressa sobretudo, nos resultados de aprendizagem dos seus alunos. Está informado é um dos fatores 
primordiais nesse contexto. Assim sendo, as escolas não podem permanecer alheias ao processo de desenvolvimento tecnológico ou à nova realidade, sob pena de perder-se em meio a todo esse processo de reestruturação educacional.

Partindo deste sentido, é importante debater a relação e a verdadeira importância da tecnologia no contexto escolar, sobretudo dentro da própria sala de aula. No entanto, hoje muitas vezes a maioria dos professores não sabe lidar quando se deparam com estes recursos midiáticos na escola. É por isso que os docentes devem buscar meios que possam orientá-los a tornar os conhecimentos mais significativos e atrativos aos seus alunos.

Assim como Ferreira (2014), Jordão (2010) também destaca a importância do professor continuar a se capacitar. Para ele, a formação do professor deve ocorrer de forma permanente e para a vida toda. Sempre surgirão novos recursos, novas tecnologias e novas estratégias de ensino e aprendizagem. O professor precisa ser um pesquisador permanente, que busca novas formas de ensinar e apoiar alunos em seu processo de aprendizagem.

Diante do revelado, é inevitável e inegável a necessidade que o educador tem de se capacitar, aprimorar e se preparar para lidar com esse "novo" que são as tecnologias digitais, e com esse novo padrão de educação e ensino que não reconhece o professor mais como o único detentor do saber, mas como mediador dele. Esse novo ambiente de aprendizagem, em que aluno e professor edificam juntos os conhecimentos, deve ser expressivo para a vida do educando.

\section{Método}

No desenvolvimento deste presente estudo foi realizada inicialmente pesquisa bibliográfica sobre o tema proposto, bem como pesquisa de campo com coleta de dados na Escola da rede pública Municipal Luís Pedro de Carvalho, no município de InhumaPI.

Como ferramenta de abordagem empregou-se dois questionários, cada um com 10 (dez) questões: (1) o primeiro questionário foi destinado aos docentes, com os quais buscou-se saber a visão dos mesmos sobre o uso dos recursos tecnológicos em sala de aula, (2) o segundo questionário foi direcionado aos gestores, onde procurou-se investigar quais as possíveis soluções para os problemas apresentados: a falta de incentivo na formação continuada para os docentes ou a tecnofobia sofrida por alguns professores frente às TICs, o que dificulta tanto a utilização como a aprendizagem dos próprios professores quanto ao domínio destes recursos tecnológicos. Desta forma, serão identificados os recursos tecnológicos e de comunicação inseridos no processo de ensino e aprendizagem e como estes são utilizados. O questionário apresentou questões do tipo mistas (objetivas e subjetivas). Quanto à amostra representativa, (quantitativa) foi coletada com um grupo de 8 (oito) professores e o núcleo gestor (dois gestores) do Ensino Fundamental das séries de $6^{\circ}$ ao $9^{\circ}$ ano da escola, da rede pública de ensino do Município de Inhuma-PI, Escola Municipal Luís Pedro de Carvalho. Para seleção dos docentes partícipes da amostra foram utilizados os seguintes critérios: a modalidade de ensino, tempo de serviço dos docentes e formação.

A pesquisa foi realizada no período de quinze dias, onde os docentes tiveram tempo suficiente para responder ao questionário para os fins destinados. 
VIII Congresso Brasileiro de Informática na Educação (CBIE 2019)

Anais do XXV Workshop de Informática na Escola (WIE 2019)

\section{Resultados e Discussões}

Os resultados adquiridos na coleta instrumento dessa pesquisa foram tabulados por meio de gráficos e apresentados de acordo com a Figura 1.

\subsection{Gestores}

Por meio da referida figura, possibilitou-se uma visualização gráfica dos resultados, alcançados por meio de um questionário que teve como objetivo analisar a formação e tempo de atuação dos gestores em estudo.

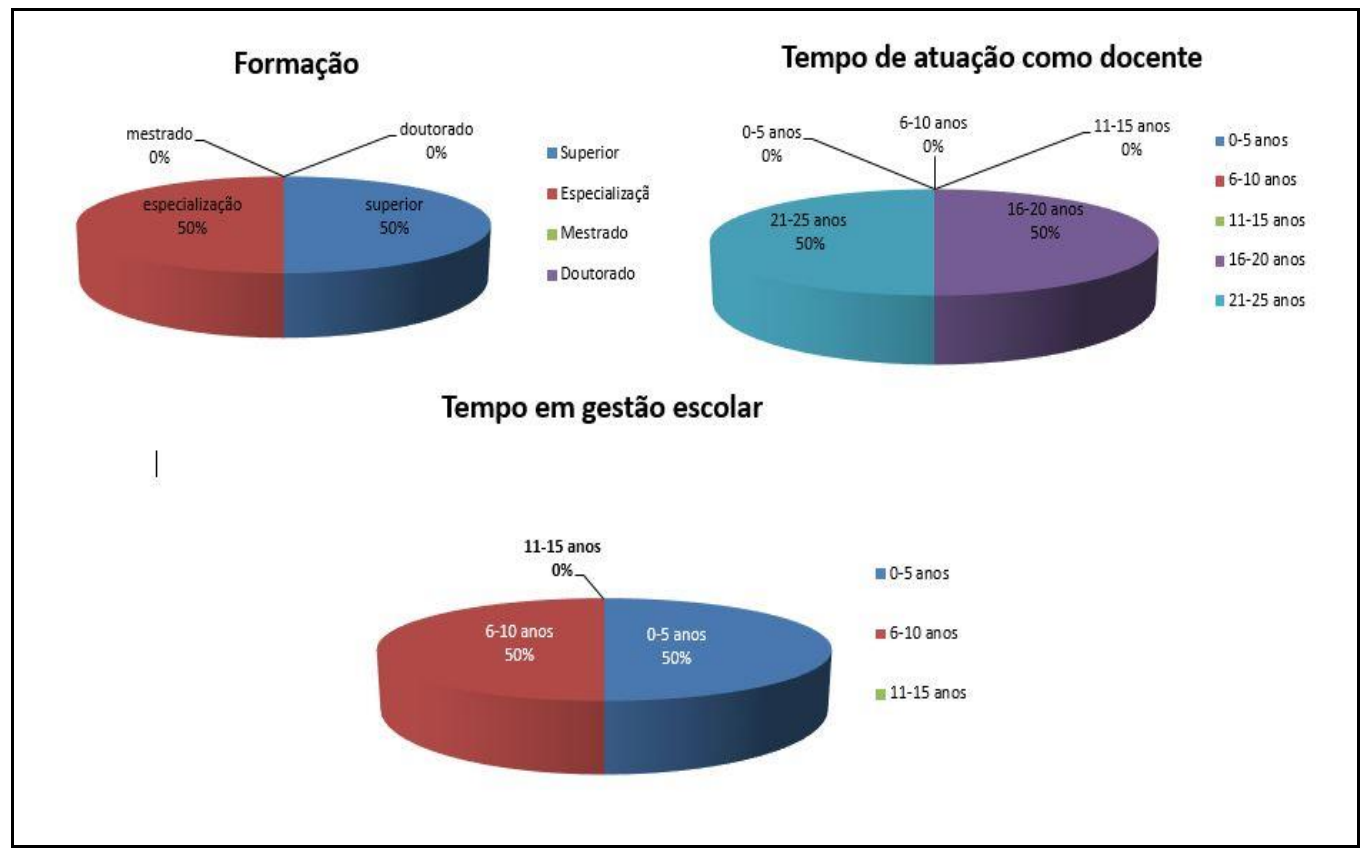

Figura 1. Informações do grau de formação e tempo de atuação dos gestores. Fonte: Autoria própria, 2018.

Após avaliação do questionário respondido pelo núcleo gestor escolar foi possível averiguar que todos possuem pós-graduação em nível de especialização e atuam como docente há mais de 15 anos. Verificou-se ainda que, como os gestores escolares atuam há mais de 6 anos, eles podem ter um conhecimento bem maior a respeito das TICs e como utilizá-las para fins pedagógicos.

Relativo à oferta de recursos tecnológicos disponíveis que podem ser utilizados em sala de aula, percebe-se que não há falta de recursos no Ensino Fundamental da Escola Municipal Luis Pedro de Carvalho, pois conforme declaram os gestores e professores da própria escola, tais recursos se fazem presentes, embora sejam em quantidade menor. Portanto, o que se precisa é saber usá-los e procurar meios para capacitarem os profissionais dessa escola, para fazer desses recursos uma importante ferramenta de ensino. Também os gestores percebem que em sua equipe de docentes, o uso dos recursos tecnológicos em sala de aula é muito frequente. E quanto ao grau de interesse dos professores em utilizar as TICs em sala de aula, afirma-se que os professores se apresentaram interessados. Considerando que, de acordo com gestores e professores, os alunos despertam um grande interesse através da tecnologia em sala de aula, as TICs são poderosas ferramentas no trabalho pedagógico, estimulando e auxiliando a aprendizagem e tornando-a agradável (Figura 2). 
VIII Congresso Brasileiro de Informática na Educação (CBIE 2019)

Anais do XXV Workshop de Informática na Escola (WIE 2019)

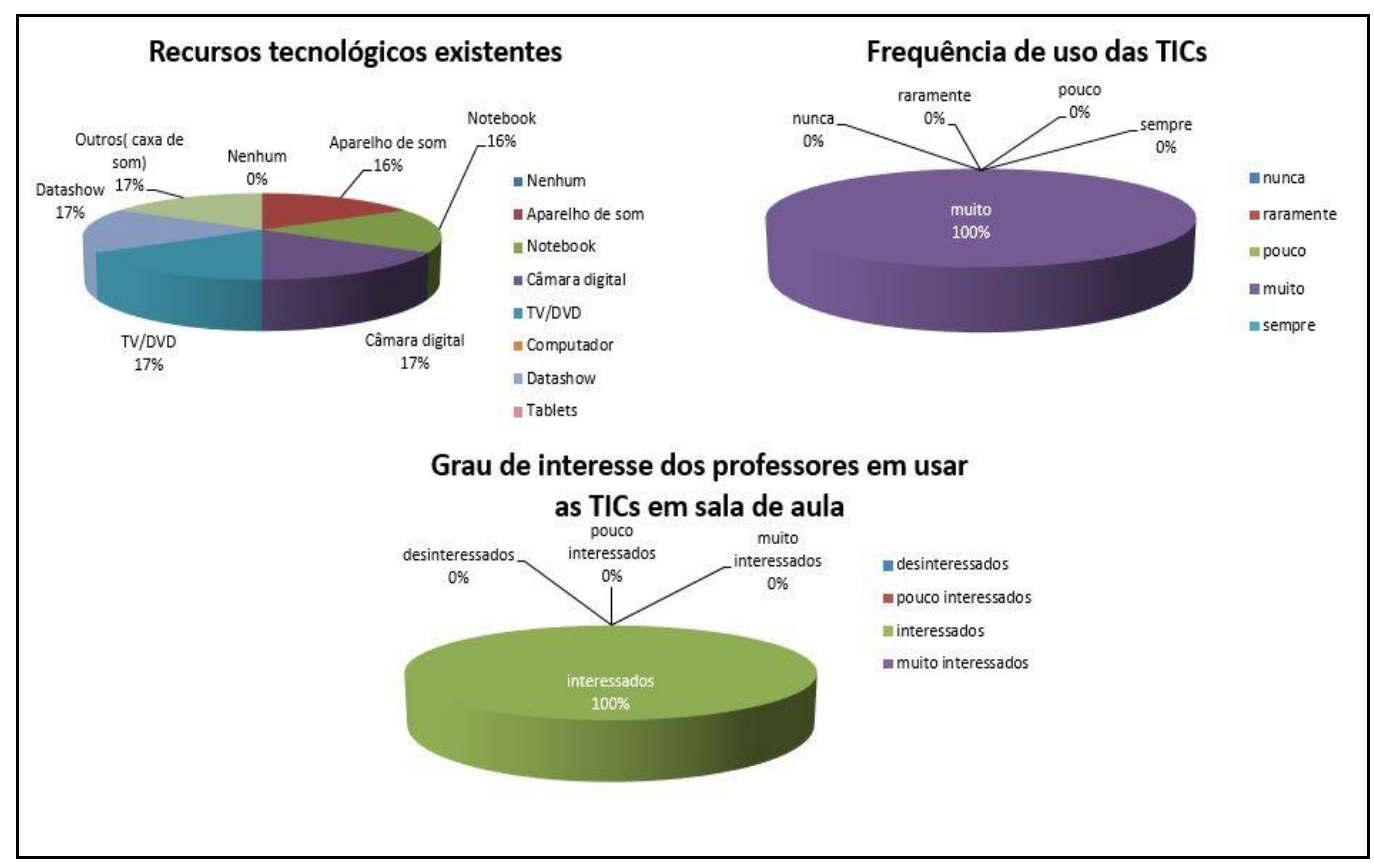

Figura 2. Informações de recursos existentes, frequência de uso e grau de interesse em usar as TICs em sala de aula. Fonte: Autoria própria, 2018.

\subsection{Docentes}

O segundo questionário foi respondido por 8 (oito) docentes do $6^{\circ}$ ao $9^{\circ}$ ano do Ensino Fundamental da Escola Municipal Luis Pedro de Carvalho, do Município de Inhuma-PI, para averiguar os dados informados na Figura 3.

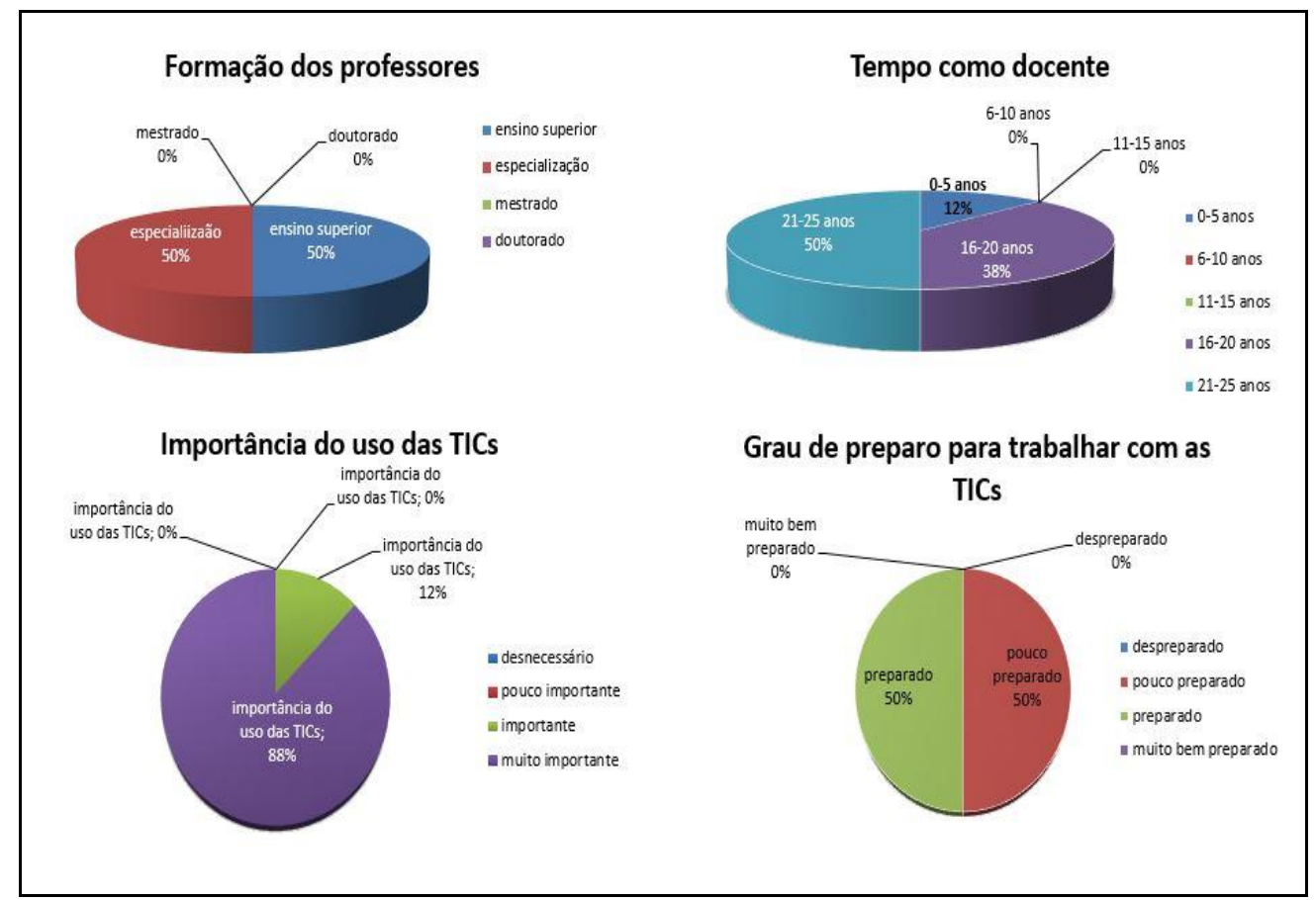

Figura 3. Informações sobre a formação, tempo de atuação como docente, importância do uso e grau de preparo para trabalhar com as TICs. Fonte: Autoria própria, 2018. 
Considerando os dados coletados, percebe-se que todos os docentes possuem ensino superior e especialização, o que faz com que acreditemos que estão em constante busca pelo conhecimento e novas formações. Todos atuam há bastante tempo na docência e também como educador do Ensino Fundamental e a maioria dos professores considera muito importante o uso das TICs na sala de aula. Já quanto ao grau de preparo que os mesmos apresentam para trabalhar com as TICs, metade dos docentes respondeu ao questionário que se sente pouco preparado, enquanto a outra metade afirma que se sente preparado. Os recursos disponíveis na escola são muitos, pois todos os professores garantiram ter acesso a um grande número dos recursos tecnológicos previamente listados: aparelho de som, notebook, câmera digital, TV/DVD, computador e Datashow. Entretanto, utilizar as TICs não é o mesmo que fazer delas uma ferramenta de ensino e aprendizagem. Embora os docentes já façam uso dessas Tecnologias de Comunicação e Informação no Ensino Fundamental da Escola Municipal Luis Pedro de Carvalho, ainda pode-se explorar em quantidade bem maior esses recursos.

\section{Conclusão}

Os aparatos tecnológicos são importantes ferramentas de apoio no contexto escolar, auxiliando e proporcionando uma melhor qualidade na aprendizagem e na prática pedagógica docente, já que o uso desses recursos torna as aulas mais dinâmicas, divertidas e muito mais agradáveis durante o período de permanência na escola. Entretanto, os resultados da pesquisa indicaram que é necessária a capacitação dos professores para o uso das TICs como auxílio à educação, pois de nada adianta haver tecnologia sem profissionais qualificados e aptos a usá-las.

Observou-se também que há a necessidade de uma capacitação docente a nível de mestrado e doutorado, já que nesse trabalho de pesquisa nenhum professor apresentou essa titulação.

A falta de preparo e falta de recursos citados no questionário como sendo a maior dificuldade encontrada pelos docentes para o uso das tecnologias em sala de aula pode ser superada através de políticas públicas que possam ofertar cursos de formação para professores sobre as TICs em sala de aula.

Portanto, o professor pode e deve buscar meios que o capacite para fazer o uso das tecnologias em sua prática pedagógica. Os gestores podem também agir de forma que venham a buscar parcerias que auxiliem nesse processo e procurem alternativas que possibilitem implantar o uso das Tecnologias da Informação e Comunicação no Projeto Político Pedagógico da escola, pois tais atitudes pode ser uma boa iniciativa para inserir as TICs como ferramenta do processo de ensino e aprendizagem. Portanto, concluiu-se que, apesar do papel que as tecnologias representam para o processo de ensino e aprendizagem, nada virá substituir um professor qualificado, criativo e valorizado.

Como perspectiva para trabalhos futuros pode-se, a partir das vertentes aqui apresentadas, buscar e implantar na escola em foco, soluções que possam sanar as deficiências que os docentes possuem no que se refere às TICs de forma a oportunizálos, vivenciar uma mudança de postura e prática frente às novas tecnologias e ao processo de ensino e aprendizagem em nossa educação, promovendo assim novos meios de formação para os docentes. 
VIII Congresso Brasileiro de Informática na Educação (CBIE 2019)

Anais do XXV Workshop de Informática na Escola (WIE 2019)

\section{Referências}

Almeida, M. E. B. T. M. (2000). O computador na escola: contextualizando a formação de professores- praticar e teoria, refletir a prática.

Faria, E. (2004). O professor e as novas tecnologias. Florianópolis.

Ferreira, M. (2014). Novas tecnologias na sala de aula. Paraíba.

Jordão, T. C. (2010). Recursos digitais de aprendizagem. Revista Tecnologias na Educação ano1, (1).

Moran, J. M. (2004). Os novos espaços de atuação do professor com as tecnologias. Revista diálogo educacional, 4(12), 1-9.

Oliveira, A. (2007). O uso das tecnologias digitais na modificação da prática educativa escolar. Maceió.

Peña, M. D. L. D. J. (2004). Ambientes de aprendizagem virtual: O desafio á prática docentes. S/D.

Santos, G., Maffezzolli, A. P., \& Galvão, A. (2017). O Uso da Tecnologia de Informação e Comunicação-TIC na Formação Inicial de Professores de uma Instituição de Ensino Superior no Município de Itaituba/Pará. In Anais do Workshop de Informática na Escola (Vol. 23, No. 1, p. 855).

Silva, A. A., Nunes, A. C., Barbosa, J. F. S., de Oliveira Garcia, L. L., dos Santos, L. S., de Albuquerque, N. L. B., \& de Assis, T. (2018). Informática Aplicada à Educação Básica nas Escolas Públicas: Formação de Educadores de Penedo/AL para o Uso das TDIC. In Anais do Workshop de Informática na Escola (Vol. 24, No. 1, p. 588).

Valente, J. A. (2005). Pesquisa, comunicação e aprendizagem com o computador. O papel. 